\title{
Meta-Analysis of the Association between Fibroblast Growth Factor 23 and Mortality and Cardiovascular Events in Hemodialysis Patients
}

\author{
Shaohui Gao Jinsheng Xu Shenglei Zhang Jingjing Jin \\ Departments of Nephrology, The Fourth Hospital of Hebei Medical University, Shijiazhuang, PR China
}

\section{Keywords}

Fibroblast growth factor $23 \cdot$ Mortality $\cdot$ Cardiovascular events $\cdot$ Hemodialysis $\cdot$ Meta

\footnotetext{
Abstract

Introduction: This study was conducted to ensure the correlation between fibroblast growth factor 23 (FGF23) and death and cardiovascular events in hemodialysis patients. Methods: We conducted a literature search of PubMed database to April 2018 for relevant articles that reported the association between FGF23 and risk of all-cause mortality and cardiovascular disease (CVD) events. The meta-analysis was performed using the Revman 5.3 software. Results: A total of 7 articles were included, and all reported mortality in hemodialysis patients, and 3 reported cardiovascular events in hemodialysis patients. Since the current reagent can detect C-terminal FGF23 (cFGF23) and intact-FGF23 (iFGF23), we discuss the association between CFGF23 and iFGF23 and
}

death and cardiovascular events in hemodialysis patients. The correlation between serum iFGF23 levels and death in hemodialysis patients: high levels of iFGF23 vs. low levels of iFGF23: RR 1.14, 95\% Cl (1.01-1.30), $p=0.04\left(I^{2}=0 \%, p=0.38\right)$. The correlation between serum $C$-terminal levels and death in hemodialysis patients: high levels of CFGF23 versus low levels of cFGF23: RR 1.39, 95\% Cl (1.21-1.59), $p<0.001\left(I^{2}=\right.$ $2 \%, p=0.38$ ). The correlation of serum iFGF23 levels with cardiovascular events: high levels of iFGF23 versus low levels of iFGF23: RR 1.21, 95\% Cl (1.13-1.30), $p<0.001\left(I^{2}=0 \%, p=\right.$ $0.49)$. A paper has reported the association between $C F G F 23$ and CVD events, so we did not conduct meta-analysis. Conclusions: Elevated serum FGF23 levels are positively associated with all-cause mortality and cardiovascular events in hemodialysis patients, with a 14 or $39 \%$ increase in all-cause mortality and a $21 \%$ increased risk of cardiovascular events.

C 2019 The Author(s)

Published by S. Karger AG, Basel

\begin{tabular}{|c|c|c|}
\hline KARGER & $\begin{array}{l}\text { (ङ) } 2019 \text { The Author(s) } \\
\text { Published by S. Karger AG, Basel }\end{array}$ & $\begin{array}{l}\text { Karger } \\
\text { Open access }\end{array}$ \\
\hline $\begin{array}{l}\text { E-Mail karger@karger.com } \\
\text { www.karger.com/bpu }\end{array}$ & $\begin{array}{l}\text { This article is licensed under the Creat } \\
\text { NonCommercial-NoDerivatives } 4.0 \text { Int } \\
\text { NC-ND) (http://www.karger.com/Ser } \\
\text { Usage and distribution for commercial } \\
\text { tribution of modified material requires }\end{array}$ & $\begin{array}{l}\text { Commons Attribution- } \\
\text { ational License (CC BY- } \\
\text { es/OpenAccessLicense). } \\
\text { poses as well as any dis- } \\
\text { ten permission. }\end{array}$ \\
\hline
\end{tabular}




\section{Introduction}

The fibroblast growth factor 23 (FGF23) protein comprises 251 amino acids, which is a full-length form of a $32-\mathrm{kDa}$ protein [1]. FGF23 is a member of the FGF family, which contains the N-terminal portion of the processing site [2] and the C-terminal part interacts with $\alpha$-Klotho [3], and mainly synthesized and secreted by osteocyte and osteoblast. Subtilisin-like proprotein convertases cleave the intact FGF23 (iFGF23) protein between Arg179 and Ser 180 to generate non-active $\mathrm{N}$ - and C-terminal fragments [4], so there are 3 forms in the blood: N-terminal FGF23, C-terminal FGF23 (cFGF23) and full-length iFGF23. But only iFGF23 is believed to be able to bound the FGFR1c/a-Klotho complex and activate downstream signaling pathways $[5,6]$.

It is well established that FGF23 is an important phosphate and vitamin $\mathrm{D}$ regulator and is essential for mineral and bone metabolism [7]. Under the synergistic effect of $\alpha$-Klotho, the combination of FGF23 with FGFR and heparin is the basic structure of FGF23 functioning. FGF23 has many physiological effects: (1) FGF23 binding to the FGFR-klotho complex located in the distal renal tubule downregulate the $\mathrm{Na} / \mathrm{Pi}$ cotransporter at the proximal tubule, which could reduce urinary phosphate reabsorption, increase urinary excretion, and the final result is a decrease in blood phosphate [8]; (2) FGF23 can directly inhibit $1 \alpha$-hydroxylase and stimulate 24 -hydroxylase, which reduces the synthesis of $1,25(\mathrm{OH}){ }_{2} \mathrm{D}_{3}$ and accelerates the inactivation of $1,25(\mathrm{OH})_{2} \mathrm{D}_{3}$, leading to a decrease in 1,25 $(\mathrm{OH}){ }_{2} \mathrm{D}_{3}$ levels [9]; (3) FGF23 can directly inhibit the secretion of parathyroid hormone (PTH) and directly increase the PTH by decreasing phosphate and vitamin $\mathrm{D}$, but the $\mathrm{PTH}$ is reducing in total [10]; (4) FGF23 also restrains bone mineralization [11]. These 4 major physiological effects determine the close interaction between FGF23 and phosphorus, PTH, vitamin $\mathrm{D}$, and calcium, as well as affect each other.

The past few years have seen a rapidly growing interest in testing the hypothesis that increased FGF23 level is an independent risk factor of mortality and cardiovascular disease (CVD) for hemodialysis patients [12]. At variance with healthy people, the FGF23 metabolism in chronic kidney disease (CKD) patients shows some features [13]: (1) The level of serum FGF23 in patients with CKD was significantly higher than that in the normal population; (2) FGF23 levels rises slowly as GFR declines in early CKD but progressively in CKD4-5 stages. When the patients reach the dialysis stage, FGF23 levels may be 1,000-fold higher than that in healthy individuals; (3) whether reaching the dialysis stage or not, FGF23 rises earlier than phosphate, vitamin D, and PTH. Moreover, a study found that diurnal variation of different forms FGF23 showed discrepancy [14]: iFGF23 emerged high in the morning and low in night, and was opposite to the rhythm of phosphate and PTH. The circadian rhythm of cFGF23 was relatively insignificant.

Although many studies focused on the connection FGF23 and CVD and death, but these studies are still controversial: FGF23 was associated with death in hemodialysis patients, but there was no correlation with CVD. Therefore, this literature analyzes the correlation between FGF23 and death and cardiovascular events in hemodialysis patients. In consideration of the assay to measure FGF23 and the discrepancy of circadian rhythm of cFGF23 and iFGF23, we conducted a subgroup analysis.

\section{Methods}

Data Source and Search Strategy

We performed a literature search on PubMed without time or language restriction up to April 2018 to identify studies focused on the association between FGF23 and risk of all-cause mortality and CVD events. We did the search following medical subject headings and keywords, such as FGF23 (All Fields); death, or mortality or all-cause mortality (All Fields); CVD events or CVDs (All Fields); hemodialysis or dialysis (All Fields). To avoid leaving out the relevant study, the literature search was performed by 2 authors (S.G. and S.Z.).

\section{Study Selection and Data Extraction}

We included any prospective cohort study that met the following criteria: (1) All patients in study should undergo maintenance hemodialysis for more than 3 months before enrolling in study; (2) The exposure was plasma or serum FGF23 concentrations; (3) Allcause mortality, cardiovascular mortality, and CVD events should be included in the study outcomes. HR and its 95\% CI in the study should be reported or calculated; (4) All study follow-up should be $\geq 6$ months.

Titles and abstracts were screened independently by 2 authors (S.G. and S.Z.); they discarded studies that were not pertinent to the topic. Case reports, reviews, editorials, letters, and fundamental research were excluded. The same 2 reviewers independently evaluated the remaining full-text articles on the basis of pre-stated inclusion criteria. A third reviewer (J.X.) solved the disagreements on study judgments. Data extraction and analysis were performed by 2 reviewers (S.G. and S.Z.) and independently verified by another (S.G.).

\section{Data Analysis}

Literature quality was evaluated on the Newcastle-Ottawa scale by 2 reviewers (S.G. and S.Z.) independently. To calculate summary estimates and 95\% CI of the risk for FGF23, we pooled both RRs and HRs by using either fixed-effects models or, in the presence of heterogeneity, random-effects models. The presence of heterogeneity across studies was evaluated by using the $\mathrm{Q}$ statistic 
Fig. 1. Study selection flow.

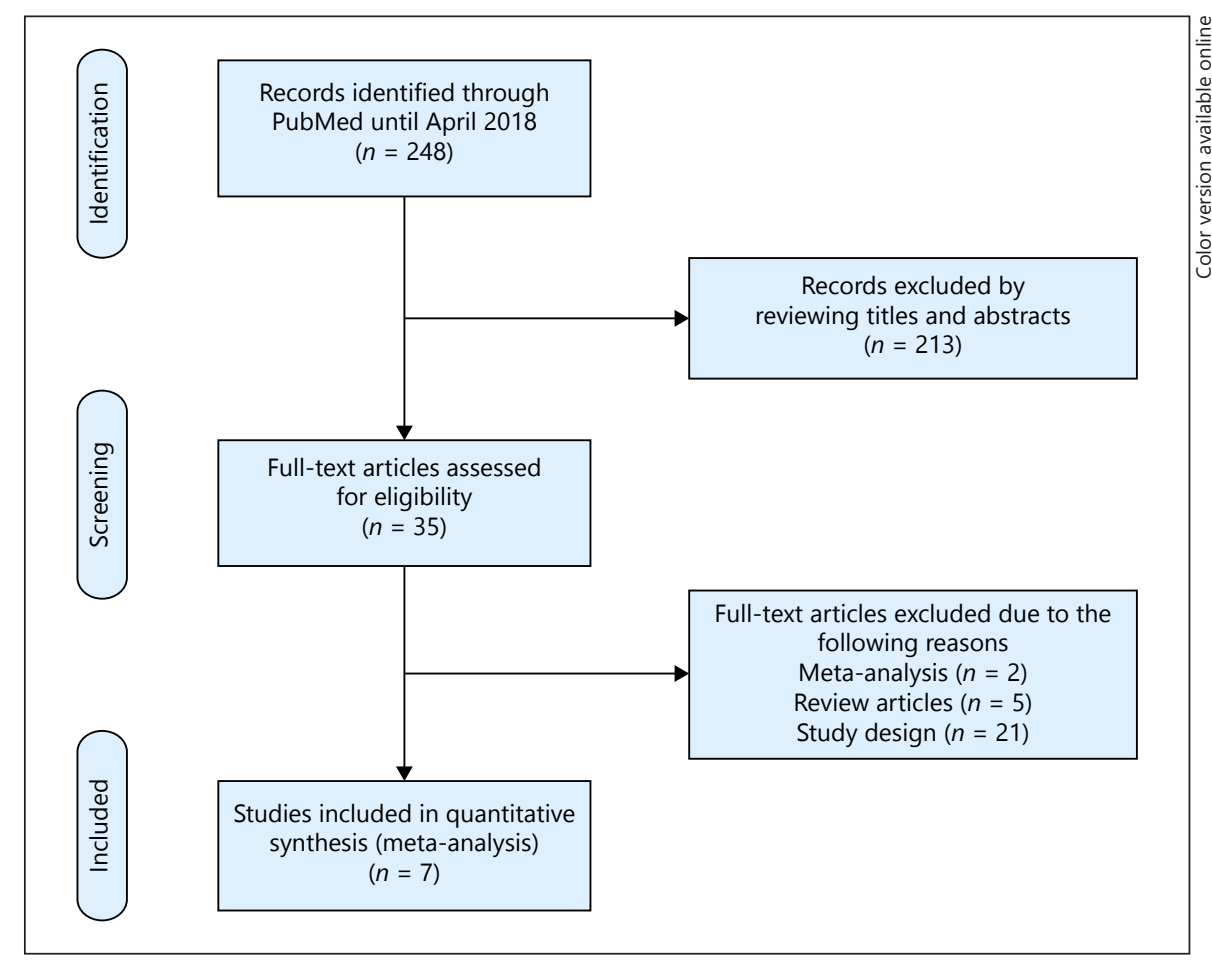

Table 1. Characteristics of 7 prospective cohort studies of FGF23 and all-cause mortality and cardiovascular events

\begin{tabular}{lllllll}
\hline Source & $\begin{array}{l}\text { Number } \\
\text { of patients }\end{array}$ & $\begin{array}{l}\text { Female, } \\
\%\end{array}$ & Age, years & $\begin{array}{l}\text { Duration, } \\
\text { months }\end{array}$ & $\begin{array}{l}\text { FGF23 } \\
\text { measurement }\end{array}$ & Outcomes \\
\hline Jean, 2009 [15] & 219 & 43.0 & $66.6 \pm 14$ & 23.2 & C-terminal & All-cause mortality \\
Hsu, 2009 [16] & 124 & 40.7 & $59.3 \pm 13.0$ & 24 & C-terminal & $\begin{array}{l}\text { All-cause mortality } \\
\text { All-cause mortality }\end{array}$ \\
Olauson, 2010 [17] & 229 & 34.9 & $55(33-68)$ & 23 & Intact & A \\
Sugimoto, 2013 [18] & 92 & 37.0 & $60.3 \pm 11.8$ & 53.2 & Intact & All-cause mortality, CVD events 8 \\
Nowak, 2014 [19] & 234 & 36.0 & $68 \pm 14$ & 30.8 & C-terminal & All-cause mortality \\
Scialla, 2015 [20] & 446 & 45.0 & $57.9 \pm 14.8$ & 40.8 & C-terminal & All-cause mortality, CVD events 9 \\
Chonchol, 2015 [21] & 670 & 55.0 & $57 \pm 14$ & 50.9 & Intact & All-cause mortality, CVD events 9 \\
\hline
\end{tabular}

with a conservative $p$ value of 0.10 . Potential publication bias was evaluated by Begg and Egger tests at the $p<0.10$ level of significance. Meta-analyses were performed using Revman 5.3 and publication bias Comprehensive Meta-Analysis V2 if data on the same outcome were provided by more than 2 studies. A $p$ value $<0.05$ was considered statistically significant.

\section{Results}

\section{Search Results}

Two hundred and forty eight potentially relevant references were initially retrieved. By screening titles and abstracts, a total of 213 citations were excluded; the peo- ple were not hemodialysis patients and the articles were reviews, case reports, or experimental studies. Among the 35 studies selected for full-text examination, 28 studies were excluded because of the following reasons: study design and outcomes were not pertinent to the criteria $(n=21)$; reviews and meta-analyses were excluded $(n=7)$. A total of 7 articles were, therefore, reviewed in detail. Figure 1 summarizes the study flow of this review.

\section{Study Characteristics}

The main characteristics of studies in the meta-analysis are presented in Table 1 . Of the 7 studies included here, 7 studies reported all-cause mortality and 3 studies 


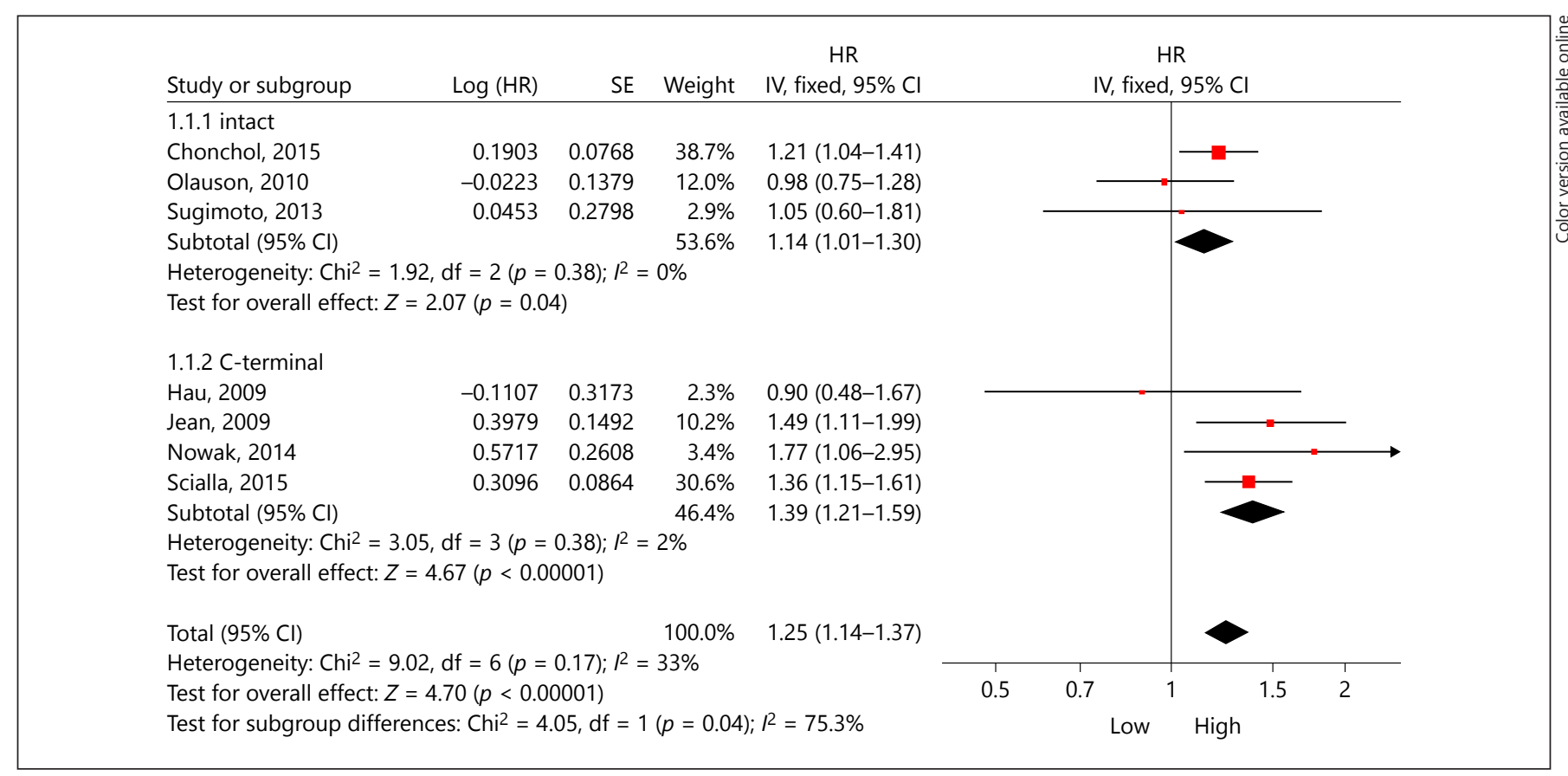

Fig. 2. The total and subgroup hazard ratio (HR) for the association between FGF23 and all-cause mortality.

\begin{tabular}{|c|c|c|c|}
\hline Begg and Mazumdar rank correlation & & Egger's regression intercept & \\
\hline \multirow[t]{3}{*}{ Kendall's S statistic (P-Q) } & -1.00000 & & \\
\hline & & Intercept & -0.28598 \\
\hline & & Standard error & 1.08714 \\
\hline \multirow[t]{2}{*}{ Kendall's tau without continuity correction } & & 95\% lower limit (2-tailed) & -3.08056 \\
\hline & & 95\% upper limit (2-tailed) & 2.50859 \\
\hline Tau & -0.04762 & $t$ value & 0.26306 \\
\hline$z$ value for tau & 0.15019 & df & 5.00000 \\
\hline$p$ value (1-tailed) & 0.44031 & $p$ value (1-tailed) & 0.40150 \\
\hline$p$ value (2-tailed) & 0.88062 & $p$ value (2-tailed) & 0.80300 \\
\hline
\end{tabular}

Fig. 3. The result of evaluated publication bias (Begg and Egger tests).

reported CVD events. Four studies tested C-terminal fragments FGF23, and 3 studies measured iFGF23. A total of 2,014 hemodialysis patients were included. Among them, $45.3 \%$ were female, and the mean age was 62.3 years. The median follow-up was 35.1 months. Seven studies are all of good quality, with the lowest 6 'stars' in Newcastle-Ottawa scale. Detailed information is shown in Table 1.

Overall, elevated FGF23 was associated with increased all-cause mortality in fixed-effect model (HR 1.25, 95\% CI 1.14-1.37, $p<0.001)$. Substantial heterogeneity was observed $\left(I^{2}=33 \%, p=0.17\right.$; Fig. 2). Subgroup analysis was performed based on FGF23 assays. High iFGF23 was associated with increased all-cause mortality in the fixedeffect model (HR 1.14, 95\% CI 1.01-1.30, $p=0.04$ ), with low heterogeneity $\left(I^{2}=0 \%, p=0.38 ;\right.$ Fig. 2$)$. In accordance with iFGF23, cFGF23 increasing is connection with allcause mortality rising in the fixed-effect model (HR 1.39; $95 \%$ CI 1.21-1.59, $p<0.001$ ), and its heterogeneity is low $\left(I^{2}=2 \%, p=0.38\right)$. The Begg and Egger tests also showed no evidence of publication bias among studies of FGF23 and all-cause mortality (Begg, $p=0.440$; Egger, $p=0.402$; Fig. 3).

As shown in Fig.4, elevated FGF23 was associated with increased CVD events in the fixed-effect model (HR 1.22, $95 \%$ CI 1.14-1.31, $p<0.001)$. The $Q$ statistics shows a low 


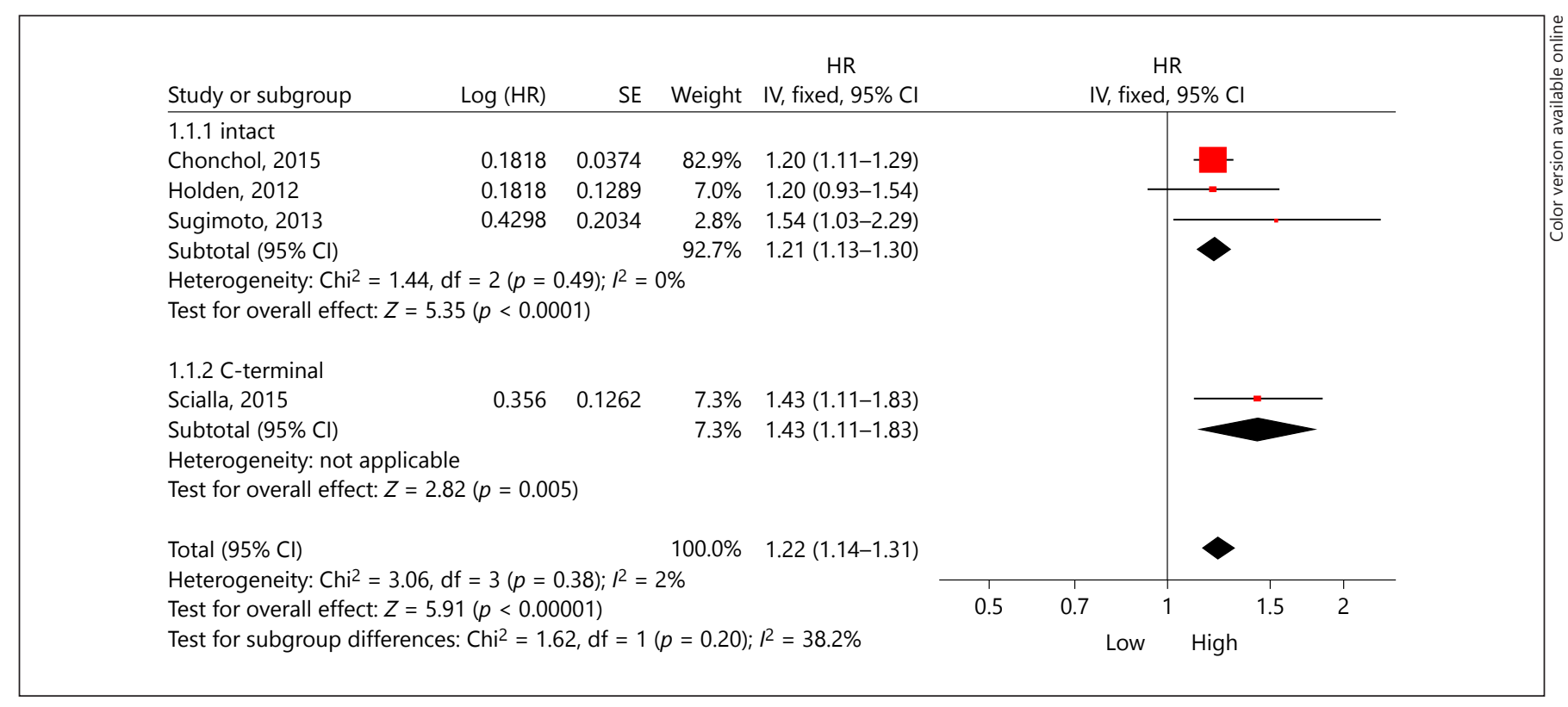

Fig. 4. The total and subgroup hazard ratio (HR) for the association between FGF23 and CVD events.

heterogeneity with $I^{2}=2 \%(p=0.38)$. Because a study using the cFGF23 assay reported the CVD events, we checked the association between iFGF23 and CVD events alone. iFGF23 increasing is connection with CVD events rising in the fixed-effect model with HR 1.21 (95\% CI $1.13-1.30, p<0.001)$, and its heterogeneity is $I^{2}=0 \%(p=$ 0.49; Fig. 4).

\section{Discussion}

The current meta-analysis found that elevated FGF23 was associated with a higher risk of $25 \%$ for all-cause mortality and $22 \%$ for CVD events in maintenance hemodialysis patients. Subgroup analyses showed that whichever form of FGF23 elevating were associated with the all-cause mortality and CVD events, indicating FGF23 predicts poor outcome in these individuals. The mechanism of elevated FGF23 levels leading to the increasing risk of mortality and CVD events remained to be not well established. According to the current evidence, hyperphosphatemia is an independent risk of death and CVD events in CKD and ESRD patients [22]. FGF23 is the strongest phosphate regulator and FGF23 inhibits the reabsorption of urinary phosphorus and synthesis of vitamin D by a-klotho expressing in proximal renal tubule [23]. In addition, FGF23 has direct cardiac and vascular poisonous $[24,25]$, independent on a-klotho. Several clinical researches have confirmed that FGF23 had an association with left ventricular mass, ejection fraction, left ventricular end-diastolic dimension, and vascular calcification $[26,27]$. These factors are associated with an adverse outcome in health individuals and hemodialysis patients.

But recent studies put forward a doubt on the association between FGF23 and mortality [28, 29]. Marthi et al. [29] confirmed the association between FGF23 and mortality by meta-analysis. But Marcais et al. [23] provided that evaluating the FGF23 without Klotho data may over highlight the detrimental effect. They proposed this assumption based on the findings FGF23 and Klotho were both cardiovascular morbidity and mortality and independent from each other [30]. Moreover, patients with high Klotho and FGF23 did not present increased morbidity and mortality [30]. Although animal model supported the Marcais's hypothesis [31], but FGF23 unexpressing in cardiomyocytes and the cardiac toxicity of FGF23 dependent on the FGFR4 $[32,33]$ may explain the effect of FGF23 and Klotho on cardiovascular morbidity and mortality independent from each other.

In accordance with Marthi et al. [29], our data support the conclusion that elevated FGF23 increases the risk of all-cause mortality and CVD. In a word, FGF23 is a potential risk prediction factor and may be help for clinical practice.
Gao/Xu/Zhang/Jin 


\section{Acknowledgments}

We thank J.J. for providing help for this article.

\section{Ethics Statement}

The authors have no ethical conflicts to disclose.

\section{Disclosure Statement}

The authors declare that they have no conflicts of interest to disclose.

\section{Funding Sources}

This work was supported by the project of the Hebei major medical Science (GL2011-51), the project of Hebei science and technology planning (16397733D) and Hebei province medical technology tracking project (G2018050).

\section{Authors Contribution}

Research idea and study design: S.G., J.X., and S.Z.; data acquisition: S.G. and S.Z.; data analysis/interpretation: S.G. and S.Z.; statistical analysis: S.G. and S.Z.; manuscript writing: S.G., J.X. and S.Z.

\section{References}

1 Takashi Y, Fukumoto S: FGF23 beyond phosphotropic hormone. Trends Endocrinol Metab 2018;29:755-767.

2 Fukumoto S, Yamashita T: FGF23 is a hormone-regulating phosphate metabolism unique biological characteristics of FGF23. Bone 2007:40:1190-1195.

3 Yamazaki Y, Tamada T, Kasai N, Urakawa I, Aono Y, Hasegawa H, et al: Anti-FGF23 neutralizing antibodies show the physiological role and structural features of FGF23. J Bone Miner Res 2008:23:1509-1518.

4 Shimada T, Mizutani S, Muto T, Yoneya T, Hino R, Takeda S, et al: Cloning and characterization of FGF23 as a causative factor of tumor-induced osteomalacia. Proc Natl Acad Sci U S A 2001:98:6500-6505.

5 Chen G, Liu Y, Goetz R, Fu L, Jayaraman S, $\mathrm{Hu}$ MC, et al: $\alpha$-Klotho is a non-enzymatic molecular scaffold for FGF23 hormone signalling. Nature 2018:553:461-466.

6 Urakawa I, Yamazaki Y, Shimada T, Iijima K, Hasegawa H, Okawa K, et al: Klotho converts canonical FGF receptor into a specific receptor for FGF23. Nature 2006:444:770-774.

7 Komaba H, Fukagawa M: FGF23: a key player in mineral and bone disorder in CKD. Nefrologia 2009:29:392-396.

8 Razzaque MS, Lanske B: The emerging role of the fibroblast growth factor-23-klotho axis in renal regulation of phosphate homeostasis. J Endocrinol 2007:194:1-10.

9 Hasegawa H, Nagano N, Urakawa I, Yamazaki Y, Iijima K, Fujita T, et al: Direct evidence for a causative role of FGF23 in the abnormal renal phosphate handling and vitamin D metabolism in rats with early-stage chronic kidney disease. Kidney Int 2010:78: 975-980.

10 Suva LJ, Friedman PA: PTH regulation of FGF23 fragments: a tail in two acts. Endocrinology 2017:158:1106-1108.

11 Murali SK, Roschger P, Zeitz U, Klaushofer K, Andrukhova O, Erben RG: FGF23 Regulates bone mineralization in a $1,25(\mathrm{OH}) 2 \mathrm{D} 3$ and klotho-independent manner. J Bone Miner Res 2016:31:129-142.

12 Jovanovich A, Chonchol M: Chronic kidney disease: reductions in FGF-23 levels associated with improved outcomes. Nat Rev Nephrol 2015:11:572-573.

13 Wolf M: Forging forward with 10 burning questions on FGF23 in kidney disease. J Am Soc Nephrol 2010:21:1427-1435.

14 Smith ER, Cai MM, McMahon LP, Holt SG: Biological variability of plasma intact and Cterminal FGF23 measurements. J Clin Endocrinol Metab 2012:97:3357-3365.

15 Jean G, Terrat JC, Vanel T, Hurot JM, Lorriaux C, Mayor B, et al: High levels of serum fibroblast growth factor (FGF)-23 are associated with increased mortality in long haemodialysis patients. Nephrol Dial Transplant 2009;24:2792-2796.

16 Hsu HJ, Wu MS: Fibroblast growth factor 23: a possible cause of left ventricular hypertrophy in hemodialysis patients. Am J Med Sci 2009;337:116-122.

17 Olauson H, Qureshi AR, Miyamoto T, Barany $\mathrm{P}$, Heimburger $\mathrm{O}$, Lindholm B, et al: Relation between serum fibroblast growth factor-23 level and mortality in incident dialysis patients: are gender and cardiovascular disease confounding the relationship? Nephrol Dial Transplant 2010;25:3033-3038.

18 Sugimoto H, Ogawa T, Iwabuchi Y, Otsuka K, Nitta K: Relationship between serum fibroblast growth factor-23 level and mortality in chronic hemodialysis patients. Int Urol Nephrol 2014;46:99-106.

19 Nowak A, Friedrich B, Artunc F, Serra AL, Breidthardt T, Twerenbold R, et al: Prognostic value and link to atrial fibrillation of soluble Klotho and FGF23 in hemodialysis patients. PLoS One 2014;9:e100688.

20 Scialla JJ, Parekh RS, Eustace JA, Astor BC, Plantinga L, Jaar BG, et al: Race, mineral homeostasis and mortality in patients with endstage renal disease on dialysis. Am J Nephrol 2015;42:25-34.
21 Chonchol M, Greene T, Zhang Y, Hoofnagle AN, Cheung AK: Low vitamin D and high fibroblast growth factor 23 serum levels associate with infectious and cardiac deaths in the HEMO study. J Am Soc Nephrol 2016;27: 227-237.

22 Haynes R, Wheeler DC: Chronic kidney disease: does serum phosphate predict death and ESRD in CKD patients? Nat Rev Nephrol 2013:9:438-439.

23 Takeshita A, Kawakami K, Furushima K, Miyajima M, Sakaguchi K: Central role of the proximal tubular $\alpha$ Klotho/FGF receptor complex in FGF23-regulated phosphate and vitamin D metabolism. Sci Rep 2018:8: 6917.

25 Leifheit-Nestler M, Kirchhoff F, Nespor J, Richter B, Soetje B, Klintschar M, et al: Fibroblast growth factor 23 is induced by an activated renin-angiotensin-aldosterone system in cardiac myocytes and promotes the profibrotic crosstalk between cardiac myocytes and fibroblasts. Nephrol Dial Transplant 2018:33:1722-1734.

25 Yamada S, Giachelli CM: Vascular calcification in CKD-MBD: roles for phosphate, FGF23, and Klotho. Bone 2017: 100:87-93.

26 Nassiri AA, Hakemi MS, Safar-Pour R, Ahmadi A, Tohidi M, Kashani BS, et al: Association of serum intact fibroblast growth factor 23 with left ventricular mass and different echocardiographic findings in patients on hemodialysis. J Transl Int Med 2016:4:135141.

27 Breznik S, Ekart R, Hren M, Rupreht M, Balon BP: Radiographic assessment of vascular calcification, aortic pulse wave velocity, anklebrachial index and fibroblast growth factor-23 in chronic hemodialysis patients. Ther Apher Dial 2013:17:378-383.

28 Pelletier S, Fouque D: Fibroblast growth factor-23 is not a single bystander in chronic kidney diseasem. J Am Soc Nephrol 2018:29: 2601. 
29 Marthi A, Donovan K, Haynes R, Wheeler DC, Baigent C, Rooney CM, et al: Fibroblast growth factor-23 and risks of cardiovascular and noncardiovascular diseases: a metaanalysis. J Am Soc Nephrol 2018:29:20152027.

30 Marcais C, Maucort-Boulch D, Drai J, Dantony E, Carlier MC, Blond E, et al: Circulating klotho associates with cardiovascular morbidity and mortality during hemodialysis. J Clin Endocrinol Metab 2017:102:31543161.

31 Hu MC, Shi M, Cho HJ, Adams-Huet B, Paek J, Hill K, et al: Klotho and phosphate are modulators of pathologic uremic cardiac remodeling. J Am Soc Nephrol 2015:26:1290-1302.
32 Grabner A, Amaral AP, Schramm K, Singh S, Sloan A, Yanucil C, et al: Activation of cardiac fibroblast growth factor receptor 4 causes left ventricular hypertrophy. Cell Metab 2015:22: 1020-1032.

33 Itoh N, Ohta H, Nakayama Y, Konishi M: Roles of FGF signals in heart development, health, and disease. Front Cell Dev Biol 2016:4:110. 